\title{
SENIOR TOURISTS' PERCEPTIONS OF BUS STOP ENVIRONMENTS USED IN COLLABORATIVE DESIGN
}

\author{
MANUELA PIRES ROSA ${ }^{1 *} \&$ JOSÉ DA CRUZ LOPES ${ }^{2 \dagger}$ \\ ${ }^{1}$ Centre for Spatial and Organizational Dynamics, University of Algarve, Portugal \\ ${ }^{2}$ Polytechnic Institute of Viana do Castelo, Portugal
}

\begin{abstract}
Presently, universal accessibility is seen as an attribute of sustainable cities and territories, as it contributes to the quality of built environments, friendly environmental behaviors and social inclusion. Accessible built environments are required; so urban spaces, buildings, transport vehicles, information technology communication and services must include the process of "Age Sensitive Design" that attends to ageing and considers the perceptions of elderly people, who tend to have mobility, vision, hearing and cognitive issues or problems. Active ageing requires that there be an accessible tourism strategy, where the conditions related with elderly peoples' mobility are important. The research project Accessibility for All in Tourism (ACCES4ALL) focuses on modal interfaces that are designed to be age friendly. Its main objective is to develop a pilot study: an accessible, smart and sustainable bus stop to be located at Faro International Airport. The layout is beyond the consideration of international technical norms and considers human diversity. The design process is collaborative, focusing on the users' needs. It is a humanized process that requires an integrated team of civil engineering, architecture, geography, design, information, and communication and tourism professionals, who consider senior tourists' perceptions of bus stop environments. A questionnaire was developed for the elderly tourist aged 60 or over, about their mobility and perceptions of bus stop environments, and the importance of some attributes for their mobility. This paper describes some results of the ACCES4ALL project that indicate elderly tourists have the perception of an accessible bus stop's attributes, mainly in urbanistic aspects: sidewalks and bus stops with barrier-free space, non-slip surfaces, well lit, with soft ramps. They consider it important to have shelters with places to rest. Most consider that tactile and chromatic markings, QR (quick response) codes and near field communication (NFC) technology are not important for their mobility.

Keywords: accessibility, age sensitive design, bus stop, collaborative design, disability, elderly people, accessible tourism, sustainable tourism, tourism.
\end{abstract}

\section{INTRODUCTION}

Sustainable tourism demands important aspects in travel destinations, such as ecological and cultural integrity, environmental quality, economic viability, accessibility, social equity, quality of life and well-being. These attributes are essential in the planning and management of mobility systems, and they are particularly important for the sustainability of territories and for tourism activity in particular.

There is a holistic vision of sustainable mobility; as this contributes to economic development, territorial cohesion, social inclusion, the consumption of renewable natural resources, and takes into consideration the public's and ecosystem's health.

These are very difficult sustainable development goals, as nowadays in developed countries, travel mobility involves a massive use of motorized vehicles, which are dependent, in general, of fossil-fuel-based energy and generate greenhouse gas emissions. The tourism sector contributes to these problems.

\footnotetext{
* ORCID: http://orcid.org/0000-0001-5017-6408

$\dagger$ ORCID: http://orcid.org/0000-0003-1667-8118
} 
Transportation represents almost a quarter of Europe's greenhouse gas emissions [1]. The European strategy for low-emission mobility considers low and zero-emission vehicles, digital technologies, and the role that cities and local authorities play in the implementation of these measures. It encourages active travel like cycling and walking, use of public transportation, car-sharing and car-pooling schemes.

To get more utilization of public transportation, interfaces and pedestrian infrastructures must have a combination of quality characteristics, where universal design is outstanding. In fact, traditional urban public transportation systems, worldwide, are generally designed for a healthy population and they rarely consider the needs of people with disabilities [2].

The European Commission expressed its commitment to a "Barrier-Free Europe" [3] and all member states have to meet this inclusive target. The present Action Plan for the Development of Tourism in Portugal presents an opportunity, as the current ageing of the population potentiates senior tourism [4]. There are favorable conditions for the development of the senior segment in sports and health tourism, so accessible tourism must be considered.

The Research Project "Accessibility for All in Tourism" (ACCES4ALL), focuses on modal interfaces designed according to the concepts of Universal Design and Age Sensitive Design. Its main objective is to develop a pilot study: an accessible, smart and sustainable bus stop to be located at Faro International Airport, in Algarve, Portugal.

In this project, it is reinforced that transportation and outdoor spaces have created issues and concerns voiced by older people and institutions, enterprises and the associations which serve them. So, the decision-making associated with the design process goes beyond the point of view of designers and enterprises such as paying clients; but, as Zeisel said, while there might be good communication between designers and paying clients, both have a gap in their communications with the end user, and there exist gaps between these [5]. So Zeisel's userneeds gap model could be applied to the case of bus users, especially elderly persons and people with disabilities, who many times did not give input into the various stages of design and implementation processes. The present research gives the opportunity to understand the perceptions of elderly tourists about bus stop environments.

The layout of the bus stop is done beyond the consideration of technical norms and considers, also, elderly people's diversity, through a collaborative design process that focuses on the users' needs. It is a humanized process that requires an integrated team constituted of professionals in civil engineering, architecture, geography, design, information and communication, and tourism; which considers diverse senior tourists' perceptions of bus stop environments.

Thus, a questionnaire was developed for the elderly tourist, aged 60 or over, about their mobility and their perceptions of bus stop environments, and the importance of some attributes for their mobility.

This paper describes some of the results of the project ACCES4ALL. The main purpose of this study is to provide an assessment of the environments of bus stops from the perspective of older customers' experience. The main objective of the present paper is to present the senior tourists' perceptions of bus stop environments located in their own countries, and view the importance of some attributes for their mobility.

\section{CHANGING PARADIGMS IN TRANSPORTATION}

The energy sector is composed of the subsystems for generation (mainly centralized), transmission, distribution and consumption of energy; thus, in a sustainable and resilient community, emphasis must be given to decentralized systems, and to the contribution of transportation and building to energy saving. 
The paradigm of transition energy is related to the principle of "energy trias" [6], which is summarized as being the reduction of energy demand through the application of energy reduction measures (like thermal insulation, heat recovery), use of renewable energy sources for the production of energy (such as solar, wind and biomass), and application of fossil energy sources as cleanly as possible (such as high-efficiency gas boilers). In the European Union (EU), the adaptation of this approach has been translated into some measures: selection of energy source, monitoring and regulation of energy consumption, use of solar energy, reduction of energy demand and reduction of heat losses.

In the transportation sector, improved public passenger transport systems can contribute to a reduction in energy consumption. Collective transport could contribute to the reduction of individual motorized traffic in territories, offering quality in terms of safety and comfort, and responding to the needs of users.

The quality of collective transport systems depends on: system accessibility (examples, the needs of people with reduced mobility, the design of stations including intermodality, linking trip-attracting areas to public transport), affordability (example, fare levels), socially desirable services (example, concession fares), safety and security (examples, quality of lighting, surveillance system), travel convenience (examples, comfort and information), less environmental impact (example, emissions) [7]. If collective transport is made more attractive by improving standards of service and organization, and made more accessible to people whose mobility is conditioned (e.g., elderly people, tourists with trolleys), large numbers of persons will be encouraged to use it regularly.

People's disabilities influence their lives in terms of mobility and the use of transport equipment. Seniors need convenient, comfortable, safe and secure public transportation [8]. When transport is inaccessible, it can inhibit people with disabilities and/or reduced mobility from participating in society on equal terms [9].

So, the changing of paradigms in transportation is not only related with environmental issues. Integrated in the sustainable mobility context, and associated with the concept of social equity, the concept of "inclusive mobility" emerges. This issue has been discussed for the last decades, influencing the implementation of an integrated transport policy in a way that contributes to greater social justice and inclusion. It attends to human diversity in addressing the specific needs of handicapped persons and other people with reduced mobility, such as: the elderly and people with sensorial, intellectual and/or physical disabilities. Therefore, the principles of Universal Design should be incorporated into urban design and in the transport infrastructure. The elderly tend to have limited movement as a consequence of age, hearing and visual difficulties, and other difficulties regarding mental scope. As a consequence, special attention must be paid to the needs of the elderly, when requalifying urban, architectural and transport systems. The Age Sensitive Design approach should be considered.

In metropolitan cities and international airports, the deployment of multimodal interfaces can contribute to help increase the attractiveness of collective transport for all: these should be accessible to all citizens, be quick and easy to trans-ship, comfortable and safe. Due to their transfer function between means of transportation and depending on the type of travel they offer (short, medium or long-term). These interfaces should provide useful utilities, such as cafes, toilets, ATMs, etc.

In the last years, we have witnessed the emergence of bus stops for public transportation with multiple functions that go beyond people waiting for the bus. The waiting period is filled with a variety of tasks that result from the existence of Wi-Fi stations, USB chargers, MUPIs with daily information and marketing campaigns, intelligent tactile panels and LED displays 
for a real-time schedule. These innovative bus stops have been appearing in the present developed digital world and they empower access to information for everybody.

Accessible and intelligent bus stops/shelters are, presently, examples of the quality of transport interfaces and they can attract young millennials for the use of public transport and other people in the present digital age. Project ACCES4ALL researches the characteristics of these innovative bus stops, concerning the specific needs of elderly tourists, and promotes their implementation at Faro International Airport.

\section{AGEING IN URBAN ENVIRONMENTS}

\subsection{Seniors' needs in built environments}

Accessible built environments are determinants for active ageing and must be attended in countries with elderly people, as well as in their travel destinations.

The World Health Organization (WHO) regards active ageing as a lifelong process shaped by several factors (alone and acting together) that favor health, participation and security in older adult life. According to a survey, there are eight aspects of city life that overlap and interact: outdoor spaces and buildings, transportation, housing, social participation, respect and social inclusion, civic participation and employment, communication and information, community support and health services [10]. Older people and others describe a broad range of characteristics of the urban landscape and built environment that contribute to being agefriendly: there should be enough public seating; toilet facilities; dropped curbs; ramps to buildings should be standard features; lights at pedestrian crossings should be safely timed; building and housing design should be barrier-free; information materials and communication technologies should be adapted to suit diverse perceptual, intellectual and cultural needs. A literature review confirmed that buildings must be made to be accessible and have (when necessary): elevators, ramps, adequate signage, railings on stairs, stairs that are not too high or steep, non-slip flooring, resting areas with comfortable chairs, and a sufficient numbers of public toilets.

Concerning pedestrian-friendly walkways, they must be barrier-free and pavements must be well-maintained, with a smooth surface, leveled, non-slip and wide enough to accommodate wheelchairs, with low curbs that taper off to the road. Streets must have adequately spaced accessible pedestrian crossings with traffic lights (visual and audio signals) that allow sufficient time for older people to cross the road. Outdoor seating has to be available; particularly in parks, transportation stops and public spaces; and spaced at regular intervals. It is important to have clean public toilets that are easily accessible for people with varying abilities, well-signed and placed in convenient locations.

These kinds of accessible built environment increase outdoor accessibility, as perceived by the older adults who are more likely to enjoy public spaces [9].

\subsection{Seniors' needs in bus stop environments}

Personal mobility and transportation options determine an older adult's mobility. Personal mobility is directly influenced by the individual's physical and mental health status, access to personal transportation and proximity to important amenities. Mobility is, as well, indirectly affected by perceptions of safety and the person's awareness of alternative transportation options. In considering the community scale, mobility is affected by the quality and design of the transportation infrastructure (e.g. signage, traffic lights, sidewalks) and the access to reliable, affordable public transportation [10]. 
In a tourism context, the specific needs of the elderly and their families must be accommodated at station access points and loading points [11]. Designs that provide universal accessibility at stops and stations increase the equity of public transport systems and reduce operational costs [12].

Concerning the specific case of bus stops, recommendations appear to first, be associated with roads having limited amounts of traffic and low speeds, and then associated with appropriate bus stop placement. Stops in areas with high concentrations of seniors, people with disabilities and other special needs may be spaced closer together, to facilitate easier access to transit [13]. Elderly people should be able to access a bus stop within $200 \mathrm{~m}$ of their home, and within $100 \mathrm{~m}$ of any more specialized housing [14].

It is important to ensure that there is sufficient pedestrian walkway network connectivity around the bus stop, to serve these modes. Sidewalks must provide space for children to play, strollers, adults, and the growing population of older people [12]. It is important to have functional space of a walking path around the shelter. If the bus stops are not level with the road, a curb cut should provide access for disabled and elderly persons [15]. Sidewalks have to be a free of barriers and obstacles, well drained, with smooth surfaces; and pedestrian crossings must be close to the bus stop, and with adequately smooth curbs and soft slopes. Pavements must be well drained, well maintained, firm, flat and wide.

The type of bus stop depends on the type of vehicle that stops there. Vehicles have to be accessible, through elevators or soft ramps. Nowadays, an inclusive mobility paradigm demands that vehicles have low floors (around $0.30 \mathrm{~m}$ above the carriageway level) and have a kneeling mechanism that allows to be closer to the platform surface of the bus stop; but usually, they still need a ramp with a small slope for people who have difficulty boarding from or alighting to the footway, or to the bus stop platform. And the ramp is to be only soft, if the platform of the bus stop is raised to be closer to the floor height of low-floor buses. The experimental curb height is $0.28 \mathrm{~m}$, but it raises safety issues for pedestrians [16].

In urban bus vehicles, the step height and door widths are the biggest issues for children, seniors, parents with strollers, persons with baggage and persons with mobility impairments [15].

A level, paved waiting area with adequate space provides a safe, secure, non-slip surface for passengers waiting at the stop. This will provide greater access to vehicles for wheelchair users, for the elderly, and for other encumbered riders, such as parents with strollers. Another benefit is to provide an adequate waiting area, so that passengers waiting for the bus will be set back further from the curb and the flow of traffic.

In this platform, there may be a warning range, parallel to the curb, through surface markings. Usually, these show good color contrast with the surrounding paving, as tactile paving can be uncomfortable for some elderly persons [14]. On the platform, there must be room for maneuvering a wheelchair, with no obstacles.

Bus stops should provide shelter and seating. Passenger shelter is a facility designed to improve passenger comfort while waiting for public transport service. These should be provided at transfer points, at stops in weather-exposed locations or without nearby potential sheltering locations, and at stops with relatively high use by senior and child passengers [17].

Shelters must have adequate dimensions, to have room for maneuvering a wheelchair, with an appropriate number of benches and seats. Furniture must have bright color contrast with the surrounding paving and walls.

Usually, bus shelter components are transparent (glass or plastic), so that waiting passengers can see and be seen, and so, elderly people should feel more secure. These transparent materials are a problem for people with low vision, so bus shelters should also 
have tonally contrasting "bands" at different heights from the ground [18]. With these characteristics, all passengers distinguish bus stops from other street furniture.

A bus stop has to have its site in open and well-lit areas. It is important for shelters to be well lit inside, too. Shelters should have a minimum average illumination of 50 lux, measured at ground level during service hours, and a minimum of 100 lux at boarding time [15].

Benches for resting must have a suitable height, with arms and backrests with contrasting colors and a non-slip surface [16].

As bus stop poles (where there is an information flag) could be considered an obstacle for a lot of people and an age-friendly bus stop demands a shelter, it is advisable that the bus stop signs be attached inside the bus shelter. Signage for timetables, route maps and line services have to be clear, simple, easily visible and understandable. Information in Braille should be provided, too.

Visual displays of the expected arrival times for buses at stops, destinations served and any delays are helpful for all passengers, particularly for deaf and hard of hearing people. Where real-time information of this type is provided, the screen should be shielded from direct sunlight. Voice activated information systems would assist people with visual impairments and learning difficulties [18].

Some European cities have internet in their bus stops and there are quick response $(\mathrm{QR})$ codes or technology near field communication (NFC) that can increase access to the information, for those who have a smart mobile phone. Sometimes there is an interactive intelligent panel.

An age-friendly bus stop creator must consider multiple elements about it and about its environment (Fig. 1): placement must be near home, elderly centers and other amenities (urban proximity), must be located in calm traffic routes (through traffic calming measures, when possible), with accessible bus vehicles, accessible footways and floors, an accessible platform with a barrier-free waiting area, with accessible shelter, adapted benches, adequate lighting (inside the shelter and out) and accessible information. So accessibility at bus stops must consider urban aspects, specific materials, information and communication for all and have adapted urban furniture.

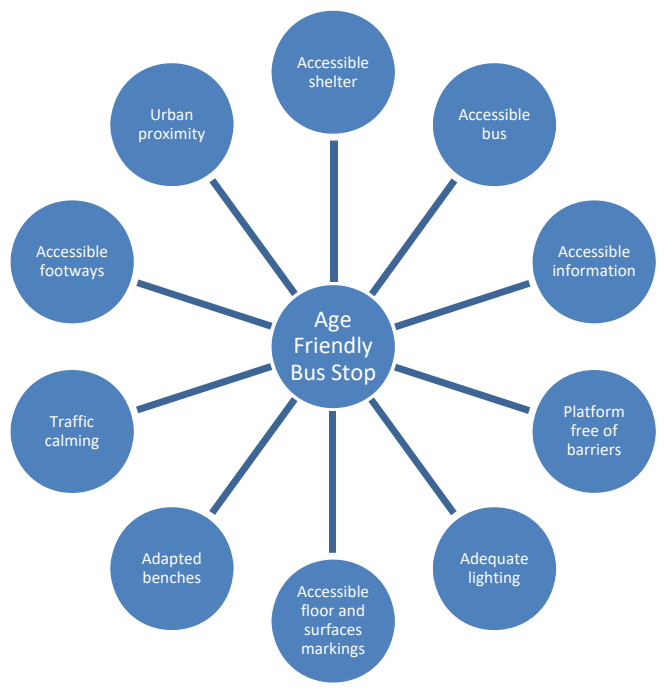

Figure 1: Characteristics of an age-friendly bus stop. 


\section{CASE STUDY: SURVEY OF THE ELDERLY TOURISTS AT FARO INTERNATIONAL AIRPORT}

\subsection{Data collection}

Within the scope of the project ACCES4ALL, surveys were carried out on elderly tourists (aged 60 years or over), to understand their perceptions about built environments and other issues. These questionnaires contain four sets of questions: information about the respondent; characterization of their mobility both where they live and in the Algarve region (as tourists in Portugal); information on their perception of universal accessibility conditions in bus stops; and their use of information, communication systems and technologies.

The inquiries, totaling 851, were conducted at Faro International Airport, at a waiting area before departure. Questionnaires were done through face-to-face interviews using paper and pencil, between April and September 2018. The choice of respondents approached was randomly ordered.

Data were introduced in an electronic file and then advanced statistical analysis capabilities of Statistical Product and Service Solutions (SPSS) were used.

\subsection{Characterization of elderly tourists}

The characterization of elderly tourists was made considering: gender, age, level of education, professional occupation, country of residence, city or town where they reside, disabilities affecting mobility and their need for technical aids to get around the town.

Of the valid inquiries, $60.6 \%$ were elderly men, $39.2 \%$ were elderly women, $0.1 \%$ were other gender and $0.6 \%$ didn't want to answer. The age group of 60-69 (44.8\%) predominated, the age group at $70-79$ years old amounted to $39.9 \%$ and only $15.4 \%$ were aged 80 or over.

Concerning their different levels of education, $2.5 \%$ had a basic level, $23.2 \%$ had reached the secondary level, $54.0 \%$ had had vocational/technical training and $20.3 \%$ had a higher level. Concerning their professional situation, $70.3 \%$ were retired, $21.7 \%$ still work full time and $4.3 \%$ work part time.

The elderly tourists came from over 30 countries, but, mainly, from the UK (40.6\%), Germany (13.8\%), Ireland (8.6\%), France (7.8\%), Spain (3.8\%), Italy (3.3\%) and Belgium (3.2\%). These elderly people live mostly in a city $(75.3 \%)$.

As ageing is usually associated with dependency, loss of functionality, and cognitive impairment, older people were asked if they have disabilities that affected their mobility, and $25.3 \%$ answer positively. The nature of their disability is mainly related with motor problems $(61.6 \%)$, hearing problems $(15.2 \%)$, visual problems $(14.8 \%)$ and orientation problems $(1.7 \%)$. We found that $17.4 \%$ of older people use technical aids to get around, $31.3 \%$ specified cane, $16.2 \%$ crutches, $12.3 \%$ tripod/quadripod and $12.3 \%$, wheelchair. We found $59.0 \%$ of older people have no limitations when using public transport, $14.1 \%$ have difficulty in walking, $13.4 \%$ have difficulty in climbing steps or stairs, $3.3 \%$ have difficulty in staying upright, $3.3 \%$ have hearing problems and $2.9 \%$ have visual problems.

\subsection{Senior perceptions of bus stop environments}

The review of international normative literature concluded that the design of an accessible bus stop considers several attributes, namely: urbanistic; urban furniture, pavements and surfaces, and information and communication.

The seniors were asked to specify their perception on the conditions for universal accessibility in bus stop environments (the surroundings of bus stops), in their daily life, and 
in the country where they live. In addition, they were asked if the listed characteristics were important for their own accessibility needs.

The majority of the elderly tourists who were asked, consider that bus stop environments have universal accessibility attributes in their countries, a minority affirmed that pedestrian crossings are safe and convenient, and they said that ramps do have a different color than the surrounding sidewalks (Fig. 2).

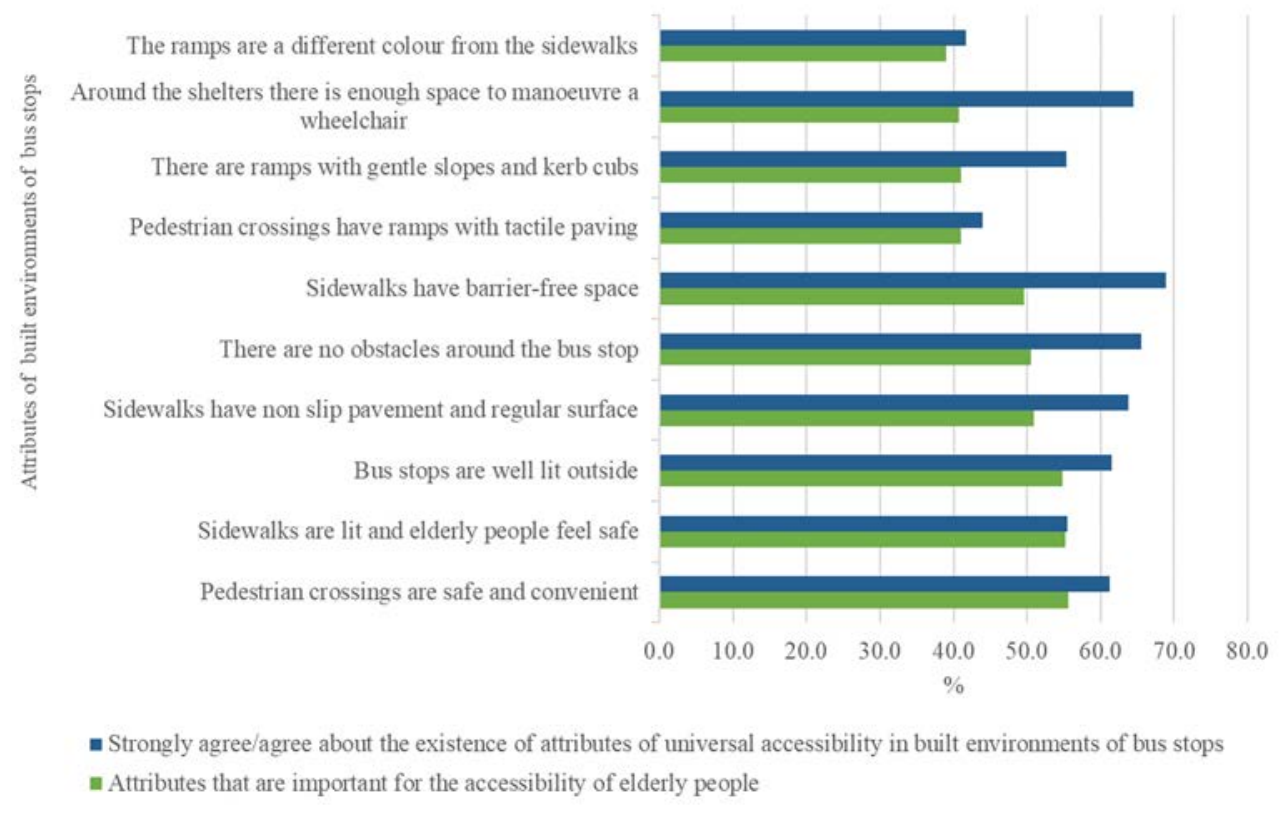

Figure 2: Perceptions of elderly tourists about the attributes of bus stop environments in their home countries.

The majority of these inquired seniors consider it is important for them that bus stop environments have universal accessibility, gave emphasis to safe and convenient pedestrian crossings, to the existence of lights in sidewalks and in the bus stops to feel safe, and to the existence of non-slip pavements and regular surfaces, plus that they need barrier-free (obstacle-free areas) around the bus stops.

They were asked to specify their perceptions on the conditions for universal accessibility at bus stops, in their daily life, in the country where they live. In addition, they were asked if the listed characteristics were important for their accessibility needs.

The majority of the elderly tourists who were inquired, consider that bus stops have universal accessibility attributes in their home countries, with places to rest in the shelters. The buses have low floors and ramps when needed. When they enter them, there is a small horizontal gap. The waiting platform has a non-slip floor, a smooth surface and the seats are of a suitable height (Fig. 3).

The majority of those inquired consider that it is important for them that bus stops have universal accessibility, giving emphasis to the existence of having room to maneuver a wheelchair on the waiting platform. They pointed out the importance of the existence of 
In the shelters there is NFC (Near Field Communication) technology

In shelters there are QR (Quick Response) codes

On the waiting platform, parallel to the kerb, there is a tactile warning strip

In the boarding area, the pavement has a different colour to the waiting platform or sidewalk

The boarding platform is higher than the sidewalk

In shelters there is information in Braille

There is tactile pavement in the boarding area

In the shelters there is space to manoeuvre a wheelchair

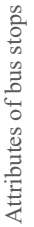

On the waiting platform there is room to manoeuvre a wheelchair

The shelters are well lit inside

In the shelters the timetables are easy to read

There is a panel with real-time waiting times

The boarding platform is almost at the same level as the vehicle floor (small vertical gap)

The seats are of a suitable height

The waiting platform has a non-slip floor and smooth surface

When the bus stops the door is near the boarding platform (small horizontal gap)
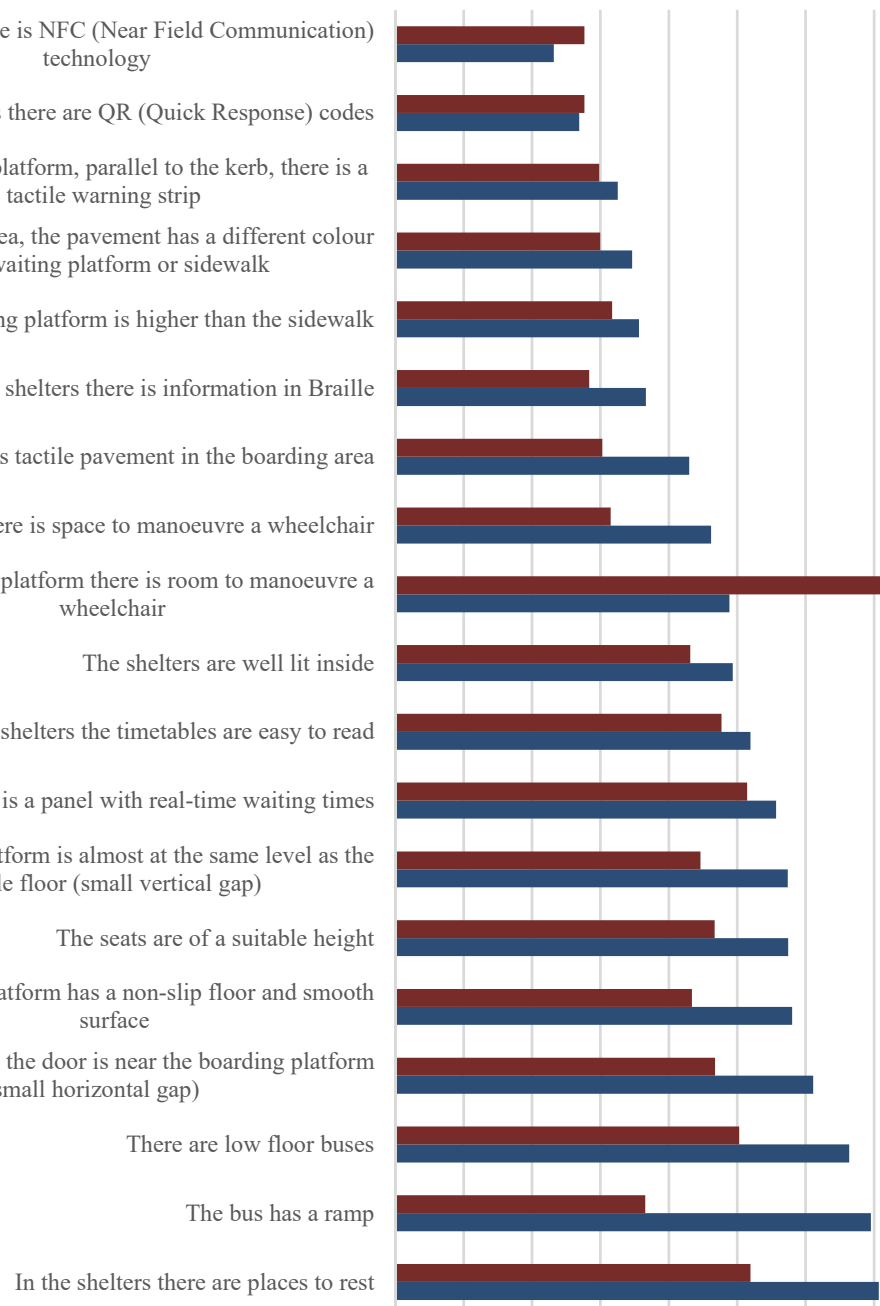

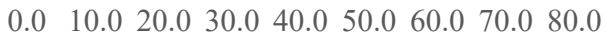

$\%$

- Strongly agree/agree about the existence of attributes of universal accessibility in bus stops

- Attributes that are important for the accessibility of elderly people

Figure 3: Perceptions of elderly tourists about the attributes of bus stop in their countries.

places to rest in the shelters, the existence of visual displays of expected arrival times of buses at the stops and the existence of buses with low floors. Those inquired elderly tourists have an effective perception of universal accessibility attributes and do consider them important. For them, bus shelters and places to rest have a valuable role in their accessibility. Seats 
should be provided in all shelters, as senior people may be able to walk to a bus stop, but for them it is very painful to stand waiting.

The importance given to aspects related with security (pedestrian crossings, sidewalks that are barrier-free, and lighting) and with low-floor buses is understandable. Low-floor buses reduce the differential height between the curb and the bus floor, which improves accessibility for elderly passengers. However, some answers were not assertive, so this could be justified by being the different perceptions of many different older persons, who all have different needs with regard to bus stop design, depending on their age group or disability. This issue must yet be researched further.

Specific seniors who need special consideration include those customers who use a wheelchair, have limited mobility, are blind or visually impaired, are hearing impaired, and those who have learning difficulties. Human diversity must consider different user needs, such as for those who use wheelchairs, crutches, walking sticks, canes, guide dogs, mobility scooters, shopping trolleys and buggies. Access to bus services must be taken into account by designers, engineers and architects, and they must work together with a collaborative approach. Any attributes that make public bus transport more accessible, whether in the design of vehicles (like low-floor buses), or in the design of access points (such as bus stops, sidewalks and pedestrian crossings) are desirable for older people and for anyone else with mobility issues. Our survey results allowed the identifying of priority areas for action, to improve the built environment associated with bus stops that are used by elderly tourists.

\section{CONCLUSIONS}

There is a growing presence of the elderly in an increasingly urbanized and globalized world. In the emergent paradigm of inclusive mobility, older people could be considered to be active participants in this change, being protagonists and beneficiaries of sustainable mobility that gives emphasis to the use of collective means of transport.

Tourism built environments must be age-friendly, to stimulate active elderly mobility by creating better conditions for sustained health, participation and security, in order to enhance the quality of life of elderly people and sustainability for destination territories. We must implement strategies concerning the adaptation of services, equipment, housing and public space towards social inclusion and accessibility. Thus, specific built environments can make a difference between age-related decline, and health and longevity, that in this context arises for implementing age-friendly bus stops.

The principal goal of Project ACCES4ALL is to present the main urbanistic attributes of bus stops, accessible for all and for elderly people in particular; and therefore, make them inclusive. The design considers several attributes, namely: (a) urbanistic; (b) urban furniture; (c) pavements and surfaces; and (d) information and communication.

Within the scope of this project, the knowledge of specific parameters allowed the construction of surveys to assess the perception of elderly tourists about their physical and communicational environment associated with bus stops. Then surveys were carried out upon elderly tourists (aged 60 or over) at Faro International Airport.

The present paper describes some of the results of this project, ACCES4ALL. The study subjects, elderly tourists, are conscious of the importance of universal accessibility's attributes for bus stops and their environments, and they have the perception that part of these attributes exist in their home country. In fact, in the EU, these have been studied and good practices were implemented concerning accessibility within transportation infrastructures.

Emphasis was given, by elderly tourists, to aspects related with their security and comfort in pedestrian crossings, lighting in sideways and bus stops, having accessible floors and surfaces, having barrier-free environments and places to rest. 
This survey was developed to be integrated in a collaborative design process, to develop relevant inclusive solutions around the elderly. The results allow us to identify the technical spatial needs and priority areas for action, to improve the built environment associated with bus stops used by elderly tourists visiting the Algarve region, through Faro International Airport. Bus stops should be re-qualified to adapt these equipment to the active ageing process of its users, which may increase the alternatives for them to choose this collective mode of transport.

A process of Age Sensitive Design, focusing on users' needs, was begun by Civil Engineering students of the Institute of Engineering of the University of Algarve. These future professionals, as urban and transportation planners, will play an important role in creating accessible places that support healthy ageing for all seniors.

To maintain Algarve's position as a tourism destination, new attractive tourism products need to be developed in a sustainable and inclusive manner, meeting the needs of local communities, as well as the environment.

The implementation of this proposed accessible, intelligent and sustainable bus stop at Faro International Airport would contribute towards promoting sustainable and intelligent mobility, senior tourism and social inclusion; thus, accessible tourism.

\section{ACKNOWLEDGEMENTS}

Project ACCES4ALL (Accessibility for All in Tourism, SAICT-POL/23700/2016) is supported by the Foundation for Science and Technology, and by FEDER, through Operational Programs CRESC Algarve 2020 and Norte 2020, Portugal.

\section{REFERENCES}

[1] European Commission, New European Strategy for Low-Emission Mobility. Communication from the Commission to the European Parliament, the Council, the European Economic and Social Committee and the Committee of the Regions. Brussels, COM(2016) 501 final, 20 Jul. 2016.

[2] Zhou, H., Hou, K., Zuo, D. \& Li, J., Intelligent urban public transportation for accessibility dedicated to people with disabilities. Sensors 2012, 12, pp. 10678-10692, 2012. DOI:10.3390/s120810678.

[3] European Commission, European Disability Strategy 2010-2020: A Renewed Commitment to a Barrier-Free Europe, 15 Nov. 2010.

[4] Turismo de Portugal, I.P., Turismo 2020, Turismo 2020: Plano de Ação para o Desenvolvimento do Turismo de Portugal (Action Plan for Tourism Development in Portugal), Turismo de Portugal, I.P. Ministério da Economia e do Emprego, 2015.

[5] Zeisel, J., Inquiry by Design, Cambridge University: Cambridge, 1984.

[6] Lysen, E.H., The trias energica: Solar energy strategies for developing countries. Eurosun Conference, Freiburg, Germany, 16-19 Sep. 1996.

[7] EU Commission, The Citizens' Network. Fulfilling the Potential of Public Passenger Transport in Europe, European Commission Green Paper, COM (95) 601 final, 29 Nov. 1995.

[8] Deby, J., TransLink bus exchanges and passenger experience: A design review (G), 2009. DOI: $10.14288 / 1.0107193$.

[9] Bekiaris, E. et al., Research for TRAN Committee: Transport and Tourism for Persons with Disabilities and Persons with Reduced Mobility, European Parliament, Policy Department for Structural and Cohesion Policies, Brussels, 2018.

[10] WHO, Global Age-Friendly Cities: A Guide, World Health Organization: Geneva, 2007. 
[11] TransLink, Transit Passenger Facility Design Guidelines, 2011.

[12] NACTO, Urban Street Design Guide, National Association of City Transportation Officials, 2012.

[13] TransLink, Transit Service Guidelines, 2018.

[14] SURFACE, The Design of Streets with Older People in Mind, Salford University Research Focus on Accessible Environments, University of Salford. www.idgo.ac.uk. Accessed on: 23 Apr. 2019.

[15] Government of Dubai, Dubai Universal Design Code, The Global Alliance on Accessible Technologies and Environments, Dubai, 2017.

[16] Northern Ireland Roads Service Transportation Unit, Bus Stop Design Guide, 2005. www.planningni.gov.uk/downloads/busstop-designguide.pdf. Accessed on: 25 Apr. 2019.

[17] BART, Building a Better Bart. Multimodal Access. Design Guidelines. Bay Area Rapid Transit, 2017.

[18] UK Department for Transport, Inclusive Mobility. A Guide to Best Practice on Access to Pedestrian and Transport Infrastructure. www.gov.uk/government/publications/ inclusive-mobility. Accessed on: 20 Apr. 2019. 